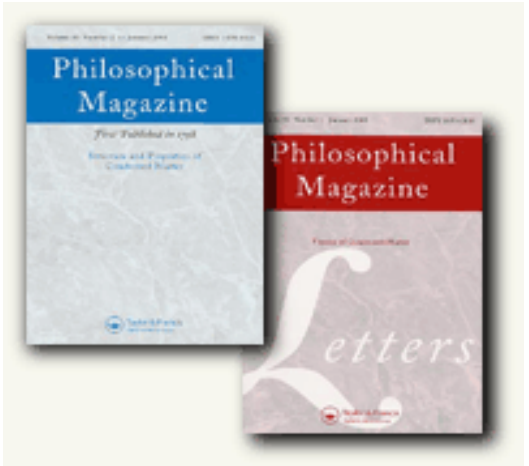

\title{
INHOMOGENEITY OF MISFIT STRESSES IN NICKEL-BASE SUPERALLOYS: EFFECT ON PROPAGATION OF MATRIX DISLOCATION LOOPS
}

\begin{tabular}{|r|l|}
\hline Journal: & Philosophical Magazine \& Philosophical Magazine Letters \\
\hline Manuscript ID: & TPHM-09-Jan-0033.R1 \\
\hline Journal Selection: & Philosophical Magazine \\
\hline Date Submitted by the & 05-Mar-2009 \\
\hline Complete List of Authors: & $\begin{array}{l}\text { Link, Thomas; Technical University Berlin, Institute for Material } \\
\text { Science and Engineering, BH 18 } \\
\text { Epishin, Alexander; Technical University Berlin, Institute for } \\
\text { Material Science and Engineering, BH 18 } \\
\text { Fedelich, Bernard; Federal Institute for Materials Research and } \\
\text { Testing, Department V.23 }\end{array}$ \\
\hline Keywords: & creep, dislocations, superalloys \\
\hline Keywords (user supplied): & misfit stresses \\
\hline
\end{tabular}

\section{今) ScholaroNE" \\ Manuscript Central}


Dr. Thomas Link (Corresponding Author)

Technical University Berlin, Institute for Material Science and Engineering, BH 18, Ernst Reuter Platz 1, 10587 Berlin, Germany

Tel: +493031426175

Fax: +493031422996

E-mail: Thomas.Link@TU-Berlin.de

Dr. Alexander Epishin

Technical University Berlin, Institute for Material Science and Engineering, BH 18,

Ernst Reuter Platz 1, 10587 Berlin, Germany

Tel: +493078981

Fax: +493031422996

E-mail: alex.epishin@yahoo.de

Dr. Bernard Fedelich

Federal Institute for Materials Research and Testing, Division V.2

Unter den Eichen 87, 12205 Berlin, Germany

Tel: +493081043104

Fax: +493081041527

E-mail: bernard.fedelich@bam.de

Number of words in the manuscript is 5322 
INHOMOGENEITY OF MISFIT STRESSES IN NICKEL-BASE SUPERALLOYS:

EFFECT ON PROPAGATION OF MATRIX DISLOCATION LOOPS

\author{
By T. Link ${ }^{1 *}$, A. Epishin ${ }^{1}$ and B. Fedelich ${ }^{2}$ \\ ${ }^{1}$ Technical University Berlin, Institute for Material Science and Engineering, BH 18, \\ Ernst Reuter Platz 1, 10587 Berlin, Germany \\ ${ }^{2}$ Federal Institute for Materials Research and Testing, \\ Unter den Eichen 87, 12205 Berlin, Germany
}

Keywords: Superalloys, Creep, Dislocations, Misfit stresses

\footnotetext{
* Corresponding author.
} 


\section{Introduction}

In nickel-base superalloys the interfacial area between $\gamma$-matrix and cuboidal $\gamma$ '-precipitates is very high with an area density of about $10^{7} \mathrm{~m}^{2} / \mathrm{m}^{3}$. Therefore the interface plays a crucial role in the structural and mechanical behaviour of superalloys. During the primary stage of high temperature creep the coherency stresses between $\gamma$ - and $\gamma^{\prime}$-phase are relaxed by interfacial dislocation networks, a process which is designated as loss of coherency of the $\gamma / \gamma^{\prime}$-interfaces. The formation mechanism of these networks was extensively studied by [1-9], with the unanimous conclusion, that during primary creep a/2 2110$\rangle$ dislocation loops are gliding on $\{111\}$-planes through matrix channels. At the intersection between $\{100\}$-interface and glide plane they leave behind $\langle 0 \overline{1} 1\rangle$ oriented dislocation segments. Cross slip of the leading segment of a matrix dislocation loop generates zigzag-shaped interfacial dislocations.

Fig. 1 gives an impression of the resulting dislocation arrangement in the $\gamma / \gamma$ ' interfaces of CMSX-4 after creep-deformation at elevated temperature and high stress. Here dislocation loops can be recognized, having about the width of the matrix channel and a direction diagonal to the $\{100\}$ habit planes of the $\gamma^{\prime}-$ cubes, which is in full agreement with the described mechanism. However, when temperatures become high and stresses low, the appearance of the interfacial dislocations changes significantly (Fig. 2).

The dislocations now mostly lie parallel to the edges of the $\gamma^{\prime}$-cubes and can hardly be recognised as trailing segments of dislocation loops. The aim of our investigations was to identify the mechanism responsible for the formation of such configurations.

E-mail address: Thomas.Link@TU-Berlin.de 


\section{Experimental}

To obtain an overview of the process of loss of coherency during primary creep, four single crystal superalloys, SRR99, CMSX-4, CMSX-10 and TMS138 were investigated, representing generation 1 to 4 in superalloy development. Table 1 shows the increasing content of refractory elements and finally the use of ruthenium in the latest alloy. In the table the constrained misfit is given, as measured in the coherent $\gamma / \gamma^{\prime}$ compound in the Primary Dendrite Arm (PDA). The misfit of the isolated phases, the unconstrained misfit, is about two times smaller [13]. The misfit averaged over the whole dendritic structure is about $50-70 \%$ of the misfit in the PDA [10].

At high temperatures around $1100^{\circ} \mathrm{C}$ superalloys are usually tested for creep under applied stresses of about $100 \mathrm{MPa}$, which are comparable with misfit stresses. The applied stresses in the hottest section of a turbine blade are even lower. This means that both applied stress and misfit stresses become relevant for the dislocation movement in the matrix channels and $\gamma / \gamma^{\prime}$-interfaces. To distinguish the effect of misfit and applied stress, dislocation structures obtained during creep tests were compared with those after annealing experiments. Table 2 gives an overview of the creep and annealing tests, presented in this paper. For all creep tests the load axis is [001].

The dislocation structures were investigated mainly by TEM (Philips, CM 30). Additionally a high resolution SEM was used (Leo Gemini $1530 \mathrm{VP}$ ), allowing to visualise interfacial dislocations via the grooves, generated by the dislocations on the $\gamma / \gamma^{\prime}$-interface [14].

The spatial distribution of misfit stresses in the $\gamma$ - and $\gamma^{\prime}$-phases was computed by the Finite Element Method (FEM) using the software ABAQUS.

\section{TEM results: Microstructural investigations}

Fig. 3 shows a typical dislocation configuration in TMS-138 after creep at $1100^{\circ} \mathrm{C}, 137 \mathrm{MPa}$ for $2 \mathrm{~h}$. The micrograph illustrates the following principles: 
Perpendicular to the load axis ("P-channels").

The average propagation direction of a loop is $\langle 100\rangle$.

The tip of the loop is narrow but with increasing distance from the tip the loop becomes wider.

Two types of cross-slip can be distinguished: when the tip of the loop approaches a channel parallel to the average propagation direction ("R-channel") it is Repelled by cross slip, but when it impinges a channel perpendicular to the propagation direction ("C-channel") it Crosses the channel and cross-slips.

The trailing zigzag line moves towards the $\gamma^{\prime}$-edge, which is parallel to the average propagation direction. Along this edge it straightens in $\langle 100\rangle$ direction.

Detailed inspection of the shape of the dislocations crossing the C-channels shows, that cross slip takes place directly at the $\gamma^{\prime}$-edges (Fig. 4). Which side of the C-channel is selected, depends on the dislocation line direction (arrows in Fig.4).

Fig. 5a shows dislocation loops in SRR99 creep deformed at $980^{\circ} \mathrm{C}, 200 \mathrm{MPa}, 45.4 \mathrm{~h}, 0.3 \%$. The beam direction is $\vec{k}_{0}=[001]$. The loop under discussion is marked by arrows 1 . It has the line vector $\vec{\xi}=\frac{1}{\sqrt{2}}[\overline{1} 10]$ and the Burgers vector $\vec{b}= \pm a / 2[0 \overline{1} 1]$, so the glide plane is (111). The average propagation direction is [100]. $\vec{b}$ has no component in the average propagation direction. This was found for all loops in all four superalloys, so it can be regarded as a general result.

Fig. $5 \mathrm{~b}$ shows the foil tilted in $[\overline{1} 01]$ orientation, so the (111) plane is now edge on. In deed the tip of the loop now appears as a line (arrows 1). Further on the left, where the loop has widened, the opposite interfacial segments are no longer lying in a common (111) plane (arrows 2). This means they have drifted by a nonconservative glide/climb movement on the lower and upper $\gamma / \gamma^{\prime}$ interfaces in opposite directions. The dislocation segments with [100] line vector give with [100] $\times[0 \overline{1} 1]$ pro forma (011) glide planes, but this is just a result of changing their original line directions from [110] and [1 10$]$ into [100] by interfacial glide/climb. So Fig. 5 confirms, that dislocation loops with $\vec{b}=a / 2\langle 110\rangle$ are gliding on 
$\{1 \overline{1} 1\}$ planes through matrix channels. Their trailing components are lying in the lower and upper interfaces respectively. The Burgers vector has a component in stress direction and the resulting interfacial dislocations have $60^{\circ}$ character. Dislocations with $\langle 100\rangle$ line directions and edge character result from interfacial movement.

Especially when no stress is applied, the effect of alignment of the interfacial dislocations in $\langle 100\rangle$ direction is very pronounced. This leads to dislocation networks, which are square rather than hexagonal. Inspection of literature shows, that interfacial dislocations with $\langle 100\rangle$ line direction and square network meshes are found typically, when temperatures are very high and stresses low, or when specimen are simply annealed (Table 3).

Fig. 6 shows such networks in SRR99, annealed at $1100^{\circ} \mathrm{C}$ for 300 h. Fig. 6a is a TEM micrograph and Fig. $6 \mathrm{~b}$ a SEM image of the same specimen. The TEM image visualises the network with a somewhat better resolution, whereas the SEM image supplies a better overview, but in any case the observed dislocation structures are practically the same.

The transition of $\langle 110\rangle$ oriented interfacial dislocations into square networks can be recognized in Fig. 7, taken with a foil of $\mathrm{TMS} 138,1100^{\circ} \mathrm{C}, 137 \mathrm{MPa}, 2 \mathrm{~h}, 0.04 \%$.

\section{FEM results and discussion}

\subsection{FEM results for coherency misfit in $\mathrm{CMSX}-4$ at $1100^{\circ} \mathrm{C}$}

During primary creep under uniaxial tensile load applied in [001] direction the matrix dislocation loops cross glide in the P-channels (001). Driving forces for this movement are the applied stress $\sigma_{33}^{a}$ and the misfit stresses $\hat{\sigma}^{m}$, given as 3D stress tensor. In this case the applied stress $\sigma_{33}^{a}$ is quite uniformly distributed within the $\gamma / \gamma^{\prime}$-microstructure because the difference of the elastic constants of $\gamma$ - and $\gamma^{\prime}$-phase 
is not large $[15,16]$. Therefore the stress $\sigma_{33}^{a}$ causes just glide on one plane but not the cross glide on another.

The misfit stresses $\hat{\sigma}^{m}$ however differ strongly in the $\gamma$ - and $\gamma^{\prime}$-phases and follow the periodicity of the $\gamma / \gamma^{\prime}$-microstructure. So the cross glide must be a consequence of local changes of the misfit stresses. To understand this effect the spatial distribution of $\hat{\sigma}^{m}(x, y, z)$ was calculated by FEM at $1100^{\circ} \mathrm{C}$. The elastic constants of $\gamma$ - and $\gamma^{\prime}$-phases were taken to be the same and equal to those of CMSX-4 at $1100^{\circ} \mathrm{C}$, i.e. $c_{11}=153 \mathrm{GPa}, c_{12}=100 \mathrm{GPa}$ and $c_{44}=89 \mathrm{GPa}[17]$. The unconstrained $\gamma / \gamma^{\prime}$-misfit in CMSX-4, $-0.25 \%$, was obtained by extrapolation of neutron diffraction data from [13] up to $1100^{\circ} \mathrm{C}$. The $\gamma^{\prime}$-volume fraction $63 \%$ was measured on SEM images showing the $\gamma / \gamma^{\prime}$-microstructure of CMSX-4 creep tested at $1100^{\circ} \mathrm{C}$. It was assumed, that the corners of the $\gamma^{\prime}$-cubes are slightly rounded with a radius $r$. The ratio between $r$ and $\gamma^{\prime}$-edge length $l, r / l \approx 20$, was measured by processing of dark field TEM images of undeformed CMSX-4. A 1/8th of the periodic cell of the $\gamma / \gamma^{\prime}$-microstructure was represented by a mesh with 671151 elements: 388157 elements for the $\gamma^{\prime}$-phase, the rest for the $\gamma$-phase. The structural model for the FEM calculations is shown in Fig. 8.

Fig. 9 represents components of the misfit stress tensor in two cross cuts along the P-channel (see Fig. 8). The normal stresses $\sigma_{22}^{m}$ and $\sigma_{33}^{m}$ are shown for a (001) plane lying in the middle of the channel $(0.5$ of the channel width $w$, Fig. 9a, b), the shear stresses $\sigma_{12}^{m}$ and $\sigma_{13}^{m}$ directly above the $\gamma / \gamma^{\prime}$-interface $(0.03$ $w)$. The area, where the $\gamma^{\prime}$-cube is lying below the matrix is marked by a dashed line and designated as $\gamma / \gamma^{\prime}$. It follows from the FEM calculations that the normal stress $\sigma_{22}^{m}$ (Fig. 9a) is compressive in the $\gamma / \gamma$ ' area with a high absolute value of about $250 \mathrm{MPa}$. In the (010)-channel however it changes its sign. The normal component $\sigma_{33}^{m}$ is tensile (Fig. 9b) but its value is much lower, namely below $50 \mathrm{MPa}$. The shear components $\sigma_{13}^{m}$ and $\sigma_{12}^{m}$ vanish in the middle of the channel but they can reach high values close to the edges of the cube. In Fig. 9 one can see, that $\sigma_{13}^{m}$ has a maximum of about $250 \mathrm{MPa}$ sharply confined to the (100) edge of the $\gamma / \gamma^{\prime}$-area. Such an inhomogeneous distribution of shear stresses along interfaces is well-known from the mechanics of composite materials. It is called "end-effect" and occurs, e.g. in 
composites reinforced by discontinuous fibres [e.g. 18]. The shear stress $\sigma_{12}^{m}$ has also a local maximum at the $\gamma^{\prime}$-corner, but it is not pronounced. It follows from the FEM results that the relevant components of the misfit tensor are $\sigma_{22}^{m}$ and $\sigma_{13}^{m}$, while the components $\sigma_{33}^{m}$ and $\sigma_{12}^{m}$ are small and therefore less important for the dislocation movement. The distribution of the components $\sigma_{11}^{m}$ and $\sigma_{23}^{m}$ follow from those for $\sigma_{22}^{m}$ and $\sigma_{13}^{m}$ by permuting the directions 1 and 2. They are not shown here, because they don't play a role for the following considerations.

\subsection{Forces acting on the dislocation loop}

Fig. 10 shows a dislocation, which has a $90^{\circ}$ kink close to the R-channel. The leading segment glides in the matrix, the trailing segments are lying in an upper and a lower $\gamma / \gamma^{\prime}$-interface. The Burgers vector is $\vec{b}=\frac{a}{2}[0 \overline{1} 1]$. The kink forms when the matrix segment cross glides from a $(\overline{1} 11)$ matrix plane to a $(111)$ plane. The leading dislocation is assumed to be the shortest segment connecting the lower and upper (001) interface along the $\{111\}$ glide plane. This gives the normalised line vectors $\vec{\xi}=\frac{1}{\sqrt{6}}[1 \overline{1} 2]$ on $(\overline{1} 11)$ and $\vec{\xi}=\frac{1}{\sqrt{6}}[\overline{1} \overline{1} 2]$ on (111). The average movement direction is [100].

The gliding component of the elastic force acting on the dislocation is (see Appendix):

$$
\vec{F}^{\text {glide }}=\tau b \vec{n} \times \vec{\xi}
$$

where $\tau$ is the resolved shear stress (RSS), $b=|\vec{b}|$ and $\vec{n}$ the glide plane normal. The RSS is given by:

$$
\tau=[\hat{\sigma}(\vec{b} / b)] \vec{n}
$$

where $\hat{\sigma}$ is the stress tensor.

It should be mentioned that $\vec{n}$ appears in both equations (1) and (2), therefore the sign of $\vec{n}$ is irrelevant. The signs of $\vec{b}$ and $\vec{\xi}$ however determine the sign of $\vec{F}^{\text {glide }}$. They have to be defined in such a way, that the edge component of a dislocation segment lying in the interfaces relaxes the misfit stresses of an alloy 
having a negative misfit. According to the discussion in [19] for a negative misfit and a Burgers vector $\vec{b}=\frac{a}{2}[0 \overline{1} 1]^{1}$, the dislocation segment in Fig. 10 lying in the lower interface must have the line vector $[110]$ on the $(\overline{1} 11)$ glide plane or to $[1 \overline{1} 0]$ on $(111)$. In the upper interface the line vectors have opposite directions.

Applying (1) for the considered glide systems one gets on the ( $\overline{1} 11)$ and (111) planes respectively:

$$
\vec{F}_{(\mp 111)}^{\text {glide }}=\tau_{(\mp 111)} \frac{a}{\sqrt{2}} \frac{1}{\sqrt{3}}[\mp 111] \times \frac{1}{\sqrt{6}}[ \pm 1,-1,2]=\tau_{(\mp 111)} \frac{a}{2}[1, \pm 1,0]
$$

The total RSS $\tau^{\text {total }}$ is the sum of the RSS $\tau^{a}$, caused by the applied stress $\sigma^{a}$ and the RSS $\tau^{m}$ caused by the misfit stress $\hat{\sigma}^{m}$.

$$
\tau_{(\mp 111)}^{\text {total }}=\tau_{(\mp 111)}^{a}+\tau_{(\mp 111)}^{m}
$$

When $\sigma^{a}$ is applied uniaxially in [001] direction, equation (2) gives for $\tau_{(\mp 111)}^{a}$ :

$$
\tau_{(\mp 111)}^{a}=\frac{1}{\sqrt{6}} \sigma_{33}^{a}
$$

$\tau_{(\mp 111)}^{a}$ is homogeneously distributed and equal for both glide systems. For $\tau_{(\mp 111)}^{m}$ (2) gives:

$$
\tau_{(\mp 111)}^{m}=\frac{1}{\sqrt{6}}\left( \pm \sigma_{12}^{m} \mp \sigma_{13}^{m}-\sigma_{22}^{m}+\sigma_{33}^{m}\right)
$$

$\tau_{(\mp 111)}^{m}$ is inhomogeneously distributed. The difference between $\tau_{(111)}^{m}$ and $\tau_{(\overline{1} 11)}^{m}$ is due to the opposite signs of the shear stresses $\sigma_{13}^{m}$ and $\sigma_{12}^{m}$ :

$$
\tau_{(111)}^{m}-\tau_{(\overline{1} 11)}^{m}=\frac{2}{\sqrt{6}}\left(-\sigma_{12}^{m}+\sigma_{13}^{m}\right) \approx \frac{2 \sigma_{13}^{m}}{\sqrt{6}}
$$

According to Fig. 9c, d the difference is caused nearly completely by $\sigma_{13}^{m}$, while the effect of $\sigma_{12}^{m}$ is negligible.

Formula (6) can be used to attain a descriptive understanding how plastic deformation works on a microscopic level. The plastic strain tensor $\hat{\varepsilon}$ produced by a dislocation gliding on a plane $\vec{n}$ over an area $A$ is: 


$$
\hat{\varepsilon}=\frac{1}{2 V}(\vec{b} \otimes \vec{A}+\vec{A} \otimes \vec{b})
$$

$V$ is the crystal volume and $\vec{A}=A \cdot \vec{n}$. In our case $\vec{b}$ is $\frac{a}{2}[0 \overline{1} 1]$ and $\vec{A}=\frac{1}{\sqrt{3}}[\mp 111]$, which gives:

$$
\hat{\varepsilon}(\mp 111)=\frac{a}{2 \sqrt{3} V}\left(\begin{array}{ccc}
0 & \pm 1 / 2 & \mp 1 / 2 \\
\pm 1 / 2 & -1 & 0 \\
\mp 1 / 2 & 0 & 1
\end{array}\right)
$$

It follows, that glide on both octahedral planes causes a contraction $\varepsilon_{22}$ perpendicular to the stress axis and an elongation $\varepsilon_{33}$ along the axis. The shear strains $\varepsilon_{12}$ and $\varepsilon_{13}$ however have opposite signs for (111) and ( 111$)$ glide, which means that they annihilate, when the loop cross glides in such a way, that a [100] average direction results. For this average movement the normal stresses $\sigma_{22}^{m}$ and $\sigma_{33}^{m}$ are important, whereas the shear stresses $\sigma_{12}$ and $\sigma_{13}$ determine locally, on which glide plane the dislocation propagates.

The RSS $\tau_{(111)}^{m}$ calculated according to (6) is shown in Fig. 11. In order to clarify how the C-channel is crossed not only the area of the C-channel but also of the neighbouring $\gamma^{\prime}$-cubes is analysed. The RSS $\tau_{(111)}^{m}$ depends very sensitively on the distance between the (001) section and the (001) $\gamma / \gamma^{\prime}$-interface. Therefore sections in 3 distances are shown: in the middle of the P-channel $0.5 w$ (a), very close to the (001) interface $0.03 w$ (c) and in-between $0.25 w$ (b).

Fig. 11 shows immediately, that a dislocation arriving from the left side on a (111) plane, is rejected when approaching the R-channel ( $\tau_{(111)}^{m}$ negative) but attracted, when it comes to the edge of the cube at the Cchannel. ( $\tau_{(111)}^{m}$ positive). Quantitative information about the distribution of $\tau_{(111)}^{m}$ in both channel types is given by Fig. 12: in Fig. 12a from the center of one $\gamma^{\prime}$-cube, crossing the R-channel (010) and ending in the center of the next cube, in Fig. 12b the same across the C-channel. For Fig 12a RSS was averaged for the distances $0.5 w, 0.25 w$ and $0.03 w$ along the matrix dislocation segment. From the cubical symmetry follows that $\sigma_{13}^{m}$ and $\sigma_{12}^{m}$ vanish along the (100) plane through the cube center (see also Fig. 9c, d).

\footnotetext{
${ }^{1}$ The sign of $\vec{b}$ is defined according to the so-called FS/RH convention [20].
} 
According to equation (7) the difference between $\tau_{(111)}^{m}$ and $\tau_{(\overline{1} 11)}^{m}$ is caused by these components. The line however, along which RSS in Fig. 12a is calculated lies in this plane and therefore in this case $\tau_{(111)}^{m}=\tau_{(\overline{1} 11)}^{m} \cdot$

We now discuss the forces acting on the leading screw dislocation of the $\frac{a}{2}[0 \overline{1} 1](111)$ glide system. The distributions of $\tau_{(\overline{1} 11)}^{m}$ can be obtained by mirroring Figs 11 and $12 \mathrm{~b}$ on the (100) plane.

From Figs 9, 11 and 12 follows:

Inside the $\gamma / \gamma^{\prime}$ area the RSS is positive. Fig. 11 and Figs. 12a, b show, that RSS is nearly constant across the P-channel in [001] direction and along this channel on the (001) plane. According to equation (6) and Fig. 9 RSS it is mostly caused by $\sigma_{22}^{m}$. The RSS increases when tensile load is applied (arrows in Fig. 12a). Applied and misfit stress $\sigma_{33}^{a}$ and $\sigma_{22}^{m}$ drive the dislocation loops through the P-channel, thus elongating the specimen by $\varepsilon_{33}$ as well as relaxing the misfit stresses by $\varepsilon_{22}$ (see equation (9)).

$\underline{\text { Close to the R-channel }(010)} \tau_{(111)}^{m}$ strongly decreases and becomes slightly negative in the center of the R-channel (Fig. 12a). The change of $\tau_{(111)}^{m}$ is mostly caused by $\sigma_{22}^{m}$ (Fig. 9). In general the matrix is under compression to attain coherency with the $\gamma^{\prime}$-phase. Locally however it is under tension, namely when the P-channel crosses the R-channel.

Crossing the C-channel (100) $\tau_{(111)}^{m}$ shows a strong oscillation near the (100) interface (Fig. 12b). From Fig. 9 follows, that the main reason is $\sigma_{13}^{m}$. The shear stress piles up in the $\gamma / \gamma^{\prime}$-area, when approaching the $\mathrm{C}$-channel. It has opposite directions on the left and right side of the C-channel, which explains the oscillation of RSS in this region.

\subsection{Cross glide at the R-channels (010)}

From the zigzag shape of the deposited interfacial dislocations (see Fig. 3) follows, that the matrix segment always changes its glide plane when approaching the R-channel (010). This type of cross slip is 
schematically shown in Fig. 10. From Fig. 12a follows, that the average RSS rapidly decreases from about $120 \mathrm{MPa}$ down to about $-10 \mathrm{MPa}$ when the dislocation moves on the (111) glide plane from the center of the $\gamma / \gamma^{\prime}$-area to the middle of R-channel. It is important that in a good approximation $\tau_{(111)}^{m}$ is equal to $\tau_{(\overline{11})}^{m}$. This is exactly correct for $x=0$ but also well achieved nearly along the complete R-channel, because the difference $\tau_{(111)}^{m}-\tau_{(\overline{1} 11)}^{m}$ is proportional to $\sigma_{13}^{m}$ (equation (7)). In this area however $\sigma_{13}^{m}$ is practically zero according to Fig. 9c. So, the shear stress on the dislocation continuously decreases, when it approachs the R-channel on $(\overline{1} 11)$, but the force increases as soon as the dislocation cross slips into (111) and thus returns back from the edge to the centre of the $\gamma / \gamma^{\prime}$-area. This misfit stress barrier at the Rchannels can be overcome if the applied stress $\sigma_{33}^{a}$ is strong enough as observed during creep under high applied stress at lower temperatures (Fig. 1).

\subsection{Cross glide at the C-channels (100)}

TEM analysis of propagating dislocation loops shows that a loop cross glides every time when crossing a C-channel (100). It is remarkable that this bend in the dislocation line takes places only on one of the two interfaces of the C-channel (100) as observed in Fig. 3 and schematically drawn in Fig. 13.

For a detailed discussion the distribution of $\tau_{(111)}^{m}$ in the (010) section across the C-channel (100) was plotted (Fig. 12b). The RSS $\tau_{( \pm 111)}^{m}$ consists of the components $\sigma_{12}^{m}, \sigma_{13}^{m}, \sigma_{22}^{m}$ and $\sigma_{33}^{m}$ (see formula (6)).

The normal stresses $\sigma_{22}^{m}$ and $\sigma_{33}^{m}$ do not depend on the sign of the $x$-component of $\vec{n}$ and $\sigma_{12}^{m}$ is zero along $y=0$ (Fig. 9d). As mentioned $\sigma_{13}^{m}$ has opposite signs on the left and right side of the C-channel. This means $\tau_{(111)}^{m}$ and $\tau_{(111)}^{m}$ are mirror symmetric with the symmetry plane lying in the middle of the Cchannel. For a better understanding of the effect of $\tau_{(111)}^{m}$ on the movement of the matrix dislocations, $\tau_{(111)}^{m}$ is given as a colour map on a longitudinal (010) cut through the middle of four neighbouring $\gamma^{\prime}-$ cubes (Fig. 14). The leading part of the dislocation loop, which is actually curved, is approximated by the 
shortest connection between the trailing dislocation segments lying in the upper (U) and lower (L) (001)interface. When the lower part of the loop reaches the channel crossing, it extends under the influence of the local maximum of $\tau_{(111)}^{m}$ towards the opposite channel side (dotted line in Fig. 14), where $\tau_{(111)}^{m}$ strongly decreases. Because of the mirror symmetry, here $\tau_{(\overline{1} 11)}^{m}$ has its maximum. Therefore this leading dislocation tip turns into screw orientation and cross slips from (111) to $(\overline{1} 11)$. The upper part of the dislocation loop follows the leading tip into the new $(\overline{1} 11)$ glide plane.

\subsection{Alignment of the interfacial dislocations parallel to the R-channels (010)}

The experiment shows that the deposited zigzag interfacial dislocations first move in the (001) interface by glide/climb but then stop near the $\gamma^{\prime}$-edge, where they align in $\langle 100\rangle$ direction parallel to the Rchannels (see Figs 2 and 3). To analyse the interaction of the kink, schematically shown in Fig.10, with the misfit stresses at the $\gamma^{\prime}$-edge, the elastic force driving a straight dislocation segment with $\vec{b}=\frac{a}{2}\left[\begin{array}{ll}0 & 1\end{array}\right]$ was calculated:

$$
\vec{F}^{e l}=\left\lfloor\left(\hat{\sigma}^{a}+\hat{\sigma}^{m}\right) \vec{b}\right] \times \vec{\xi}
$$

The line direction was approximated by $\vec{\xi}=[100]$, which considers the change of the shape of the kink: the sharp bend of the dislocation line becomes trapezoidal. Under uniaxial tension in [001] direction the component $F_{[010]}$ of the elastic force is:

$$
F_{[010]}=\frac{a}{2}\left(\sigma_{33}^{a}-\sigma_{23}^{m}+\sigma_{33}^{m}\right)
$$

One can see from (11) that on the (001) interface the dislocation is driven by the applied stress $\sigma_{33}^{a}$ as well as by the misfit stresses $\sigma_{23}^{m}$ and $\sigma_{33}^{m}$. The normal stress $\sigma_{33}^{a}$ is positive and homogeneously distributed, so it moves the dislocation always forward. The normal stress $\sigma_{33}^{m}$ supports the applied stress but its contribution is small. The shear stress $\sigma_{23}^{m}$ shows a different behavior: it is generally very small but 
has a high maximum at the transition to the R-channel (010). (The distribution of $\sigma_{23}^{m}$ can be obtained from that for $\sigma_{13}^{m}$ by permuting the directions 1 and 2). Fig. 14 shows the distribution of $F_{[010]}\left(\hat{\sigma}^{m}\right)$ for $\sigma_{33}^{a}=0$. From Fig. 15 follows, that inside the $\gamma / \gamma^{\prime}$-area $F_{[010]}\left(\hat{\sigma}^{m}\right)$ is positive and relatively small, about $50 \mathrm{MPa}$. But due to the sharp peak of $\sigma_{23}^{m}$ just before the R-channel it becomes strongly negative (below -200 MPa), thus acting as a barrier for the interfacial dislocation movement. Therefore the dislocation can not overcome this stress barrier if the applied stress is low. It stops and aligns parallel to the $\gamma^{\prime}$-edge, i.e. it is transformed from a $60^{\circ}$ - dislocation into an edge dislocation. Such interfacial edge dislocation with $\langle 001\rangle$ orientation are typical for networks in modern nickel-base superalloys, e.g. TMS138, where the $\gamma / \gamma^{\prime}$-misfit is high and therefore the effects of misfit stresses pronounced.

\section{Conclusions}

1. It is shown experimentally that under low applied stresses the matrix dislocations frequently cross glide with the periodicity length equal to that of the $\gamma / \gamma^{\prime}$-microstructure. The reason for this effect are inhomogeneous misfit stresses, which control the dislocation movement in such a way, that the resulting interfacial dislocation segments relax most effectively the misfit stresses. An outstanding role in this frequent cross glide is played by the shear components of the misfit stress. They are low on average but near the $\gamma^{\prime}$-edges attain a high value. The result is, that the dislocation loops follow an average $\langle 001\rangle$ direction on a zigzag course, being reflected when approaching R-channels parallel to this $\langle 001\rangle$ direction, and cross slipping when traversing C-channels perpendicular to this direction. Straightening of the interfacial zigzag dislocation into $\langle 001\rangle$ oriented edge dislocations is an additional effect of the shear stresses. Two sets of these $\langle 001\rangle$ dislocations can react, forming $\langle 001\rangle$ oriented square networks.

2. The described effects occur when the magnitude of misfit stresses is not much lower than the magnitude applied stress. This is the case of annealing or creep under low applied stress. 
3. The effects also should increase with temperature due to the increase of the absolute value of $\gamma / \gamma^{\prime}-$ misfit.

4. In single-crystal nickel-base superalloys of the newest generations with a high concentration of refractory elements the $\gamma / \gamma^{\prime}$-misfit is very high. The described effects explain the formation of very regular square networks with $\langle 001\rangle$ orientation as observed, e.g. in TMS138.

3. Cross glide at C-channels was explained only qualitatively and needs further investigation. For detailed understanding of its mechanism modeling of this process by dislocation dynamics is required.

\section{Acknowledgements}

Authors thank the German Research Foundation (DFG) for funding of this work (project PO 405/10-2, LI 494/4-2) and Mr. D. Noack (BAM, Berlin) for assistance in finite element modelling.

\section{References}

[1] L.J. Carroll, Q. Fang and T.M. Pollock, Metall. Trans. A 39A (2008) p.1290.

[2] A. Sato, A.Ch. Yeh, T. Kobayashi, T. Yokokawa, H. Harada, T. Murakumo and J. Zhang, A 5th generation Ni-base single crystal superalloy with superior elevated temperature properties, in Materials for advanced power engineering, J. Lecomte-Beckers, M. Carton, F. Schubert and P.J. Ennis, eds., Forschungszentrum Jülich GmbH, Jülich, 2006, p.287.

[3] J.X. Zhang, J.C. Wang, H. Harada, and Y. Koizumi, Acta Mater. 53 (2005) p.4623.

[4] J.X. Zhang, Y. Koizumi, T. Kobayashi, T. Murakumo and H. Harada, Metall. Trans A 35A (2004) p. 1911.

[5] T.M. Pollock and A.S. Argon, Acta Metall. and Mater. 42 (1994) p.1859.

[6] W. Schneider, Hochtemperaturkriechverhalten und Mikrostruktur der einkristallinen NikelbasisSuperlegierung CMSX-4 bei Temperaturen von $800^{\circ} \mathrm{C}$ bis $1100^{\circ} \mathrm{C}$, University of Erlangen-Nürnberg, Erlangen, 1993.

[7] M. Feller-Kniepmeier and T. Link, Mat. Sci. and Eng. A 113 (1989) p.191.

[8] A.K. Singh, N. Louat and K. Sadananda, Metall. Trans A 19A (1988) p.2965.

[9] A. Fredholm and J.L. Strudel, High temperature creep mechanisms in single crystals of some high performance nickel base superalloys, in High Temperature Alloys, their Exploitable Potential, J.B. Mariott, H. Herz, J. Nihoul and J. Ward, eds., Elsevier Applied Science, London, 1987, p.9. [10] U. Brückner, A. Epishin and T. Link, Acta Mater. 45 (1997) p.5223.

[11] A. Epishin, T. Link and U. Brückner, Influence of dendritic inhomogeneity on creep behaviour of a single-crystal superalloy of the $3^{\text {rd }}$ generation, DFG project PO 405/4-1; LI 494/3-1, interim report, BAM-TU Berlin, 2002.

[12] U. Brückner, BAM Berlin, unpublished research, 2008.

[13] U. Glatzel, Microstructure and Internal Strains of Undeformed and Creep Deformed Samples of a Nickel-Base Superalloy, Verlag Dr. Köster, Berlin, 1994.

[14] A. Epishin, T. Link and G. Nolze, J. of Microscopy 228 (2007) p.110. 
[15] M. Fährmann, W. Hermann, E. Fährmann, A. Boegli, T.M. Pollock and H.G. Sockel, Mat. Sci. and Eng. A260 (1999) p.212.

[16] D. Siebörger, H. Knake and U. Glatzel, Mat. Sci. and Eng. A298 (2001) p.26.

[17] B. Fedelich, J. Beckmann, M. Finn, M. Zelewski and J. Olschewski, Determination of temperature dependent elastic constants of anisotropic materials by the resonance method, Materials week 2002, DGM.e.V., 30.9-2.10.2002, Munich (CD-Rom).

[18] J.A. Nairin, Mechanics of Materials 26 (1997) p.63.

[19] T. Link, A. Epishin, M. Klaus, U. Brückner and A. Reznicek, Mat. Sci. and Eng. A 405 (2005) p.254.

[20] B.A Bilby, R. Bullough and E. Smith, Proc. Roy. Soc. A231 (1995) p.263. 


\section{Appendix: Glide force under resolved shear stress}

The projection of the Peach-Koehler formula force into the glide plane and perpendicular to the dislocation line vector $\vec{\xi}$ gives the glide component of the elastic force acting on a dislocation:

$$
F^{\text {glide }}=\{((\hat{\sigma} \cdot \vec{b}) \times \vec{\xi}] \cdot(\vec{n} \times \vec{\xi})\}
$$

where $\hat{\sigma}, \vec{b}, \vec{\xi}$ and $\bar{n}$ are respectively the stress tensor, the Burgers and line vectors, and the normal of the glide plane. Use of the Lagrange identity $(\vec{A} \times \vec{B}) \cdot(\vec{C} \times \vec{D})=(\vec{A} \cdot \vec{C}) \cdot(\vec{B} \cdot \vec{D})-(\vec{A} \cdot \vec{D}) \cdot(\vec{B} \cdot \vec{C})$ with $A=\hat{\sigma} \cdot \vec{b}, B=\vec{\xi}, C=\vec{n}$ and $D=\vec{\xi}$ gives:

$$
\begin{aligned}
& \vec{F}^{\text {glide }}=\lfloor(\hat{\sigma} \cdot \vec{b}) \cdot \vec{n}] \cdot(\vec{n} \times \vec{\xi}) \\
& F^{\text {glide }}=(\hat{\sigma} \cdot \vec{b}) \cdot \vec{n}
\end{aligned}
$$


Table 1. Investigated single crystal superalloys: Composition in wt $\%$. Constrained misfit, measured at RT in the primary dendrite arm (PDA).

\begin{tabular}{|l|l|l|l|l|l|l|l|l|l|l|l|l|}
\hline $\begin{array}{l}\text { Alloy } \\
\text { Company }\end{array}$ & Al & Ti & Cr & Co & Ni & Mo & Ru & Ta & W & Re & Hf & $\begin{array}{l}\text { Constrained } \\
\text { misfit, \% } \\
\text { Reference }\end{array}$ \\
\hline $\begin{array}{l}\text { SRR99 } \\
\text { RR,UK }\end{array}$ & 5.5 & 2.2 & 8.5 & 5.0 & 66.5 & - & - & 2.8 & 9.5 & - & - & $\approx-0.2[10]$ \\
\hline $\begin{array}{l}\text { CMSX-4 } \\
\text { C\&M, USA }\end{array}$ & 5.6 & 1.0 & 6.5 & 10.0 & 61.3 & 0.6 & - & 6.0 & 6.0 & 3.0 & - & $\approx-0.4[10]$ \\
\hline $\begin{array}{l}\text { CMSX-10 } \\
\text { C\&M, USA }\end{array}$ & 5.6 & 0.2 & 2.3 & 3.3 & 68.1 & 0.4 & - & 8.3 & 5.5 & 6.3 & - & $\approx-0.1[11]$ \\
\hline $\begin{array}{l}\text { TMS138 } \\
\text { NIMS, Japan. }\end{array}$ & 5.9 & - & 2.9 & 5.9 & 63.9 & 2.9 & 2.0 & 5.6 & 5.9 & 4.9 & 0.1 & $\approx-1.0[12]$ \\
\hline
\end{tabular}


Table 2. Creep and annealing tests in the present investigation.

\begin{tabular}{|c|c|c|c|c|c|}
\hline Material & $\mathbf{T},{ }^{\circ} \mathbf{C}$ & $\boldsymbol{\sigma}, \mathbf{M P a}$ & $\mathbf{t}, \mathbf{h}$ & $\boldsymbol{\varepsilon}, \boldsymbol{\%}$ & $\mathbf{F i g} \cdot$ \\
\hline CMSX-4 & 850 & 650 & 0.4 & 0.35 & 1 \\
\hline CMSX-4 & 1100 & 120 & 4 & 0.1 & - \\
\hline CMSX-4 & 1100 & 120 & 25 & 0.3 & - \\
\hline CMSX-10 & 1100 & 120 & 25 & 0.12 & $2 \mathrm{a}$ \\
\hline TMS-138 & 1100 & 137 & 2 & 0.04 & 3 \\
\hline SRR99 & 980 & 200 & 45.4 & 0.3 & 4 \\
\hline SRR99 & 980 & 200 & 5 & 0.06 & 5 \\
\hline CMSX-4 & 980 & 0 & 1000 & 0 & $2 \mathrm{~b}$ \\
\hline SRR99 & 1100 & 0 & 300 & 0 & $6 \mathrm{a}, \mathrm{b}$ \\
\hline CMSX-10 & 1050 & 0 & 500 & 0 & - \\
\hline
\end{tabular}


Table 3. Misfit networks with square or rectangular $\langle 100\rangle$-meshes and interfacial dislocations with $\langle 100\rangle$ line direction observed by different groups.

\begin{tabular}{|c|c|c|c|}
\hline Observation & Material & Test parameters & Reference, Fig. \\
\hline $\begin{array}{l}\langle 100\rangle \text {-meshes } \\
\text { rectangular }\end{array}$ & MK-4 & $\begin{array}{l}\text { annealing } \\
1050^{\circ} \mathrm{C}, 1150 \mathrm{~h}\end{array}$ & [1], Fig. 5b \\
\hline$\langle 100\rangle$-meshes square & TMS-196 & $\begin{array}{l}\text { creep } \\
1000^{\circ} \mathrm{C}, 245 \mathrm{MPa}\end{array}$ & [2], Fig. 3b \\
\hline$\langle 100\rangle$-meshes square & TMS-138 & $\begin{array}{l}\text { creep } \\
1100^{\circ} \mathrm{C}, 245 \mathrm{MPa}, 20 \mathrm{~h} \text { or until } \\
\text { rupture }\end{array}$ & [3], Fig. 5b, 6b, 7b \\
\hline$\langle 100\rangle$-meshes square & TMS-162 & $\begin{array}{l}\text { creep } \\
1100^{\circ} \mathrm{C}, 137 \mathrm{MPa} \text {, rupture }\end{array}$ & [4], Fig. 5d \\
\hline $\begin{array}{l}\langle 100\rangle \text { interfacial } \\
\text { dislocations }\end{array}$ & CMSX-3 & $\begin{array}{l}\text { creep } \\
1050^{\circ} \mathrm{C}, 50 \mathrm{MPa}, 48 \mathrm{~h}\end{array}$ & [5], Fig. 9 \\
\hline $\begin{array}{l}\langle 100\rangle \text { interfacial } \\
\text { dislocations }\end{array}$ & CMSX-4 & $\begin{array}{l}\text { annealing } \\
950^{\circ} \mathrm{C}, 3655 \mathrm{~h}\end{array}$ & [6], Fig. 23a \\
\hline $\begin{array}{l}\langle 100\rangle \text {-meshes } \\
\text { rectangular }\end{array}$ & CMSX-4 & $\begin{array}{l}\text { annealing } \\
1100^{\circ} \mathrm{C}, 224 \mathrm{~h}\end{array}$ & [6], Fig. 23b \\
\hline$\langle 100\rangle$-meshes square & CMSX-4 & $\begin{array}{l}\text { creep } \\
1100^{\circ} \mathrm{C}, 140 \mathrm{MPa}, 0.11 \%\end{array}$ & [6], Fig. 85a \\
\hline $\begin{array}{l}\langle 100\rangle \text { interfacial } \\
\text { dislocations }\end{array}$ & SRR99 & $\begin{array}{l}\text { annealing } \\
980^{\circ} \mathrm{C}, 1000 \mathrm{~h}\end{array}$ & [7], Fig. 5 \\
\hline $\begin{array}{l}\langle 100\rangle \text { interfacial } \\
\text { dislocations }\end{array}$ & IN713c & $\begin{array}{l}\text { annealing } \\
1000^{\circ} \mathrm{C}, 8 \mathrm{~h}\end{array}$ & [8], Fig. 5a, b \\
\hline $\begin{array}{l}\langle 100\rangle \text { interfacial } \\
\text { dislocations }\end{array}$ & alloy 221 & $\begin{array}{l}\text { creep } \\
1050^{\circ} \mathrm{C}, 140 \mathrm{MPa}, 1 \mathrm{~h}\end{array}$ & [9], Fig. 5b \\
\hline
\end{tabular}




\section{Figure captions:}

Figure 1. Interfacial dislocations in CMSX-4, creep deformed at $850^{\circ} \mathrm{C}, 650 \mathrm{MPa}, 0.4 \mathrm{~h}, 0.35 \%$. Two channels marked by arrows. Cross section, weak beam, beam direction $\vec{k}_{0}=[001]$, diffraction vector $\vec{g}=0 \overline{6} 0$. Vertical line in the middle results from the montage of two images.

Figure 2. a) Interfacial dislocations in CMSX-10, creep deformed at $1100^{\circ} \mathrm{C}, 120 \mathrm{MPa}, 25 \mathrm{~h}, 0.12 \%$. Cross section, bright field (BF), $\vec{k}_{0}=[100], \vec{g}=002$.

b) In CMSX-4, annealed at $980^{\circ} \mathrm{C}$ for $1000 \mathrm{~h} . \mathrm{BF}, \vec{k}_{0}=[001], \vec{g}=020$.

Figure 3. Dislocation loop expanding in a matrix channel during primary creep. TMS- $1381100^{\circ} \mathrm{C}, 137$ $\mathrm{MPa}, 2 \mathrm{~h}, 0.04 \%$. Cross section, $\mathrm{BF}, \vec{k}_{0}=[001], \vec{g}=020$. Tilted line in the middle results from the montage of two images.

Figure 4. Interfacial dislocations with $\vec{b}=a / 2[101]$, propagating in [010] average direction. Cross slip takes place directly on the edge of C-channels. TMS $138,1100^{\circ} \mathrm{C}, 137 \mathrm{MPa}, 2 \mathrm{~h}, 0.04 \%$, cross section. $\mathrm{BF}, \vec{k}_{0}=[100], \vec{g}=020$.

Figure 5. Dislocation loops in SRR99 creep deformed at $980^{\circ} \mathrm{C}, 200 \mathrm{MPa}, 45.4 \mathrm{~h}, 0.3 \%$.

a) Viewing direction perpendicular onto the (001) interface. Cross section, $\mathrm{BF}, \vec{k}_{0}=[001], \vec{g}=0 \overline{2} 0$.

Formatted: Bullets and Numbering

b) Foil tilted with (111) glide plane edge on. BF, $\vec{k}_{0}=[\overline{1} 01], \vec{g}=1 \overline{1} 1$.

Figure 6. Square interfacial networks in SRR99, annealed at $1100^{\circ} \mathrm{C}$ for $300 \mathrm{~h}$. (001) cut, imaged either by TEM in BF, multibeam (a) or by SEM (b).

Figure 7. Dislocation loops align in $\langle 100\rangle$ directions and form square networks. TMS $138,1100^{\circ} \mathrm{C}, 137$ $\mathrm{MPa}, 2 \mathrm{~h}, 0.04 \%$. Cross section, BF, $\vec{k}_{0}=[001], \vec{g}=220$. Tilted line in the middle results from the montage of two images.

Figure 8. Structural model for FEM calculations, given in a (100) projection. The analysed area is cubic and extends from the center of a $\gamma^{\prime}$ cube to the center of the crossing matrix channels.

Figure 9. Distributions of misfit stresses in MPa in (001) sections of the P-channel at different distances from the interface: components $\sigma_{22}^{m}$ (a) and $\sigma_{33}^{m}$ (b) at the distance $0.5 \mathrm{w}$, components $\sigma_{13}^{m}$ (c) and $\sigma_{12}^{m}$ (d) at the distance $0.03 w$. The positions of the sections are shown in Fig. 8.

Figure 10. Kink in a dislocation loop. The loop moves in a P-channel lying between two $\gamma^{\prime}$ cubes.

Figure 11. Distributions of RSS $\tau_{(111)}^{m}$ in MPa in 3 cross sections along the (001)-channel: in the channel middle $0.5 w$ (a), $0.25 w$ from the (001) interface (b) and very close to the interface $0.03 w$ (c).

Figure 12. Resolved shear stresses $\operatorname{RSS}(x, y, z)$ acting on dislocations gliding in the P-channel (001).

a) $\tau_{(111)}^{m}=\tau_{(\overline{1} 11)}^{m}$ for $x=0$ in $y$-direction across the R-channel (010).

b) $\tau_{(111)}^{m}$ for $y=0$ in $x$-direction across the C-channel (100). RSS is plotted for 3 distances from the $\gamma / \gamma^{\prime}-$ surface.

The coordinates $x=0, y=0$ belong to the corner bottom-left in Fig. 11c. 
Figure 13. Cross glide when crossing the C-channel (100).

Figure 14. Distribution of $\tau_{(111)}^{m}$ in MPa on a longitudinal (010) section with $\mathrm{y}=0$. (Middle of the cube edge in [010] direction).

Figure 15. Distribution of $F_{[010]}\left(\hat{\sigma}^{m}\right)$ in MPa on a cross section for $\sigma_{33}^{a}=0 . F_{[010]}$ drives the dislocation segment with $\vec{b}=\frac{a}{2}[0 \overline{1} 1]$ and $\vec{\xi}=[100]$ towards the [100] edge. $(|\vec{b}|$ is taken to be equal 1$)$. 


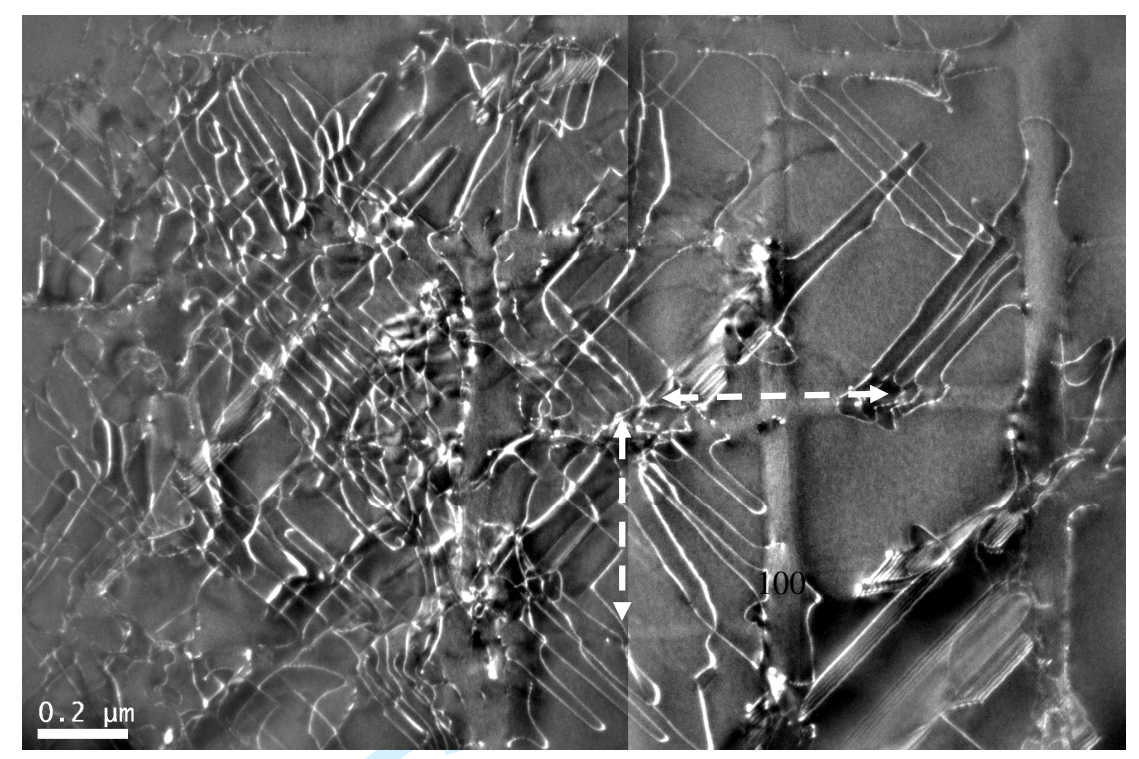

Figure 1. Interfacial dislocations in CMSX-4, creep deformed at $850^{\circ} \mathrm{C}, 650 \mathrm{MPa}, 0.4 \mathrm{~h}, 0.35 \%$. Two channels marked by arrows. Cross section, weak beam $\vec{k}_{0}=$ [001], $\vec{g}=0 \overline{6} 0$. Vertical line in the middle results from the montage of two images. 

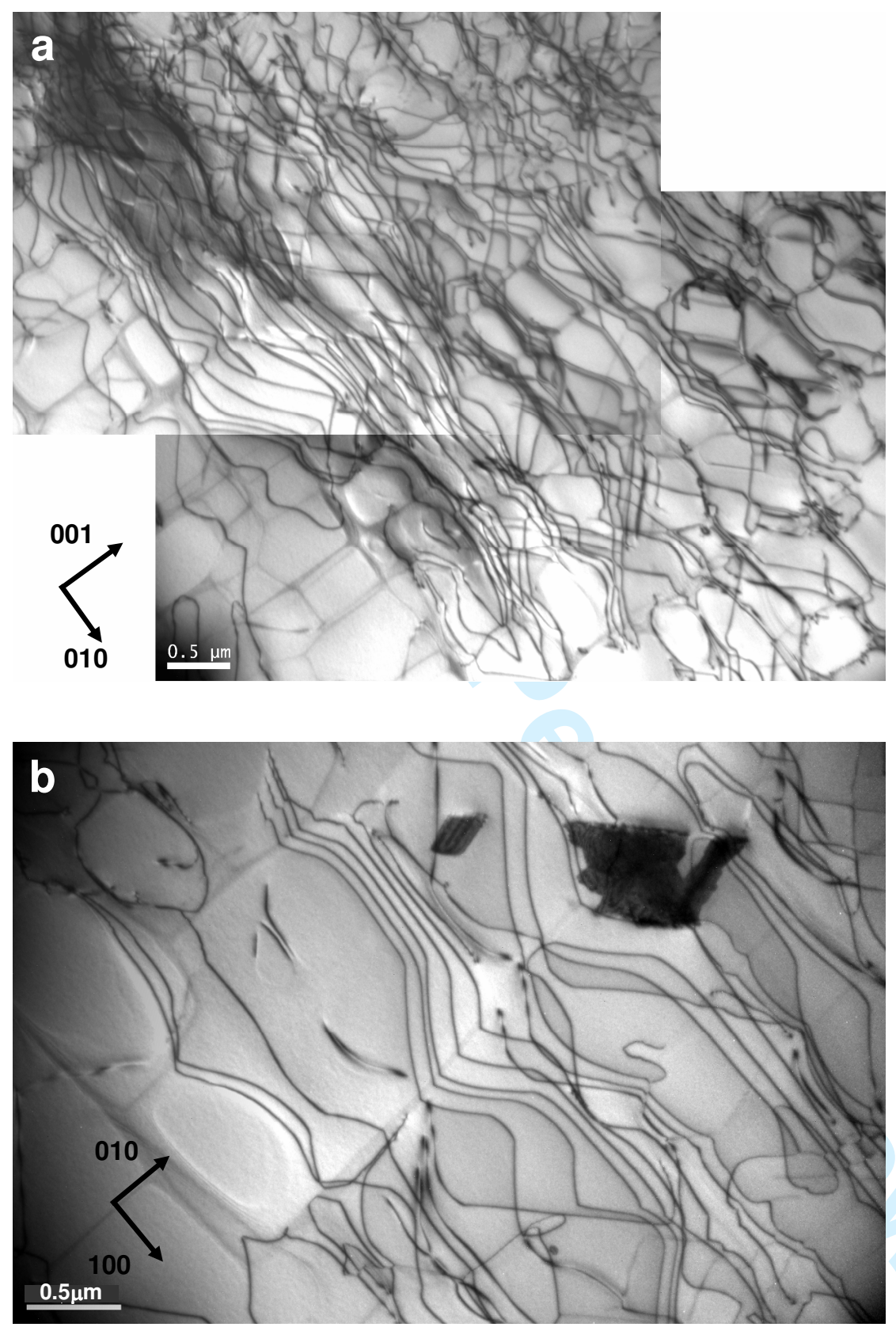

Figure 2.

a) Interfacial dislocations in CMSX-10, creep deformed at $1100^{\circ} \mathrm{C}, 120 \mathrm{MPa}, 25 \mathrm{~h}, 0.12 \%$. Cross section, bright field (BF), beam direction $\vec{k}_{0}=[100]$, diffraction vector $\vec{g}=002$. b) In CMSX-4, annealed at $980^{\circ} \mathrm{C}$ for $1000 \mathrm{~h}$. BF, $\vec{k}_{0}=[001], \vec{g}=020$. 
1

2

3

4

5

6

7

8

9

10

11

12

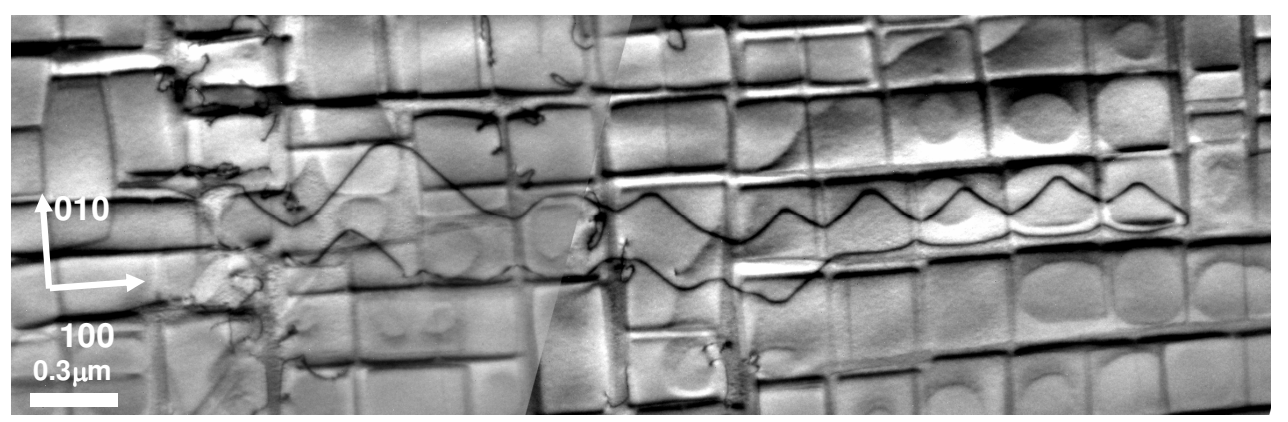

Figure 3. Dislocation loop expanding in a matrix channel during primary creep. TMS- $1381100^{\circ} \mathrm{C}, 137$ $\mathrm{MPa}, 2 \mathrm{~h}, 0.04 \%$. Cross section, $\mathrm{BF}, \vec{k}_{0}=[001], \vec{g}=020$. Tilted line in the middle results from the montage of two images. 


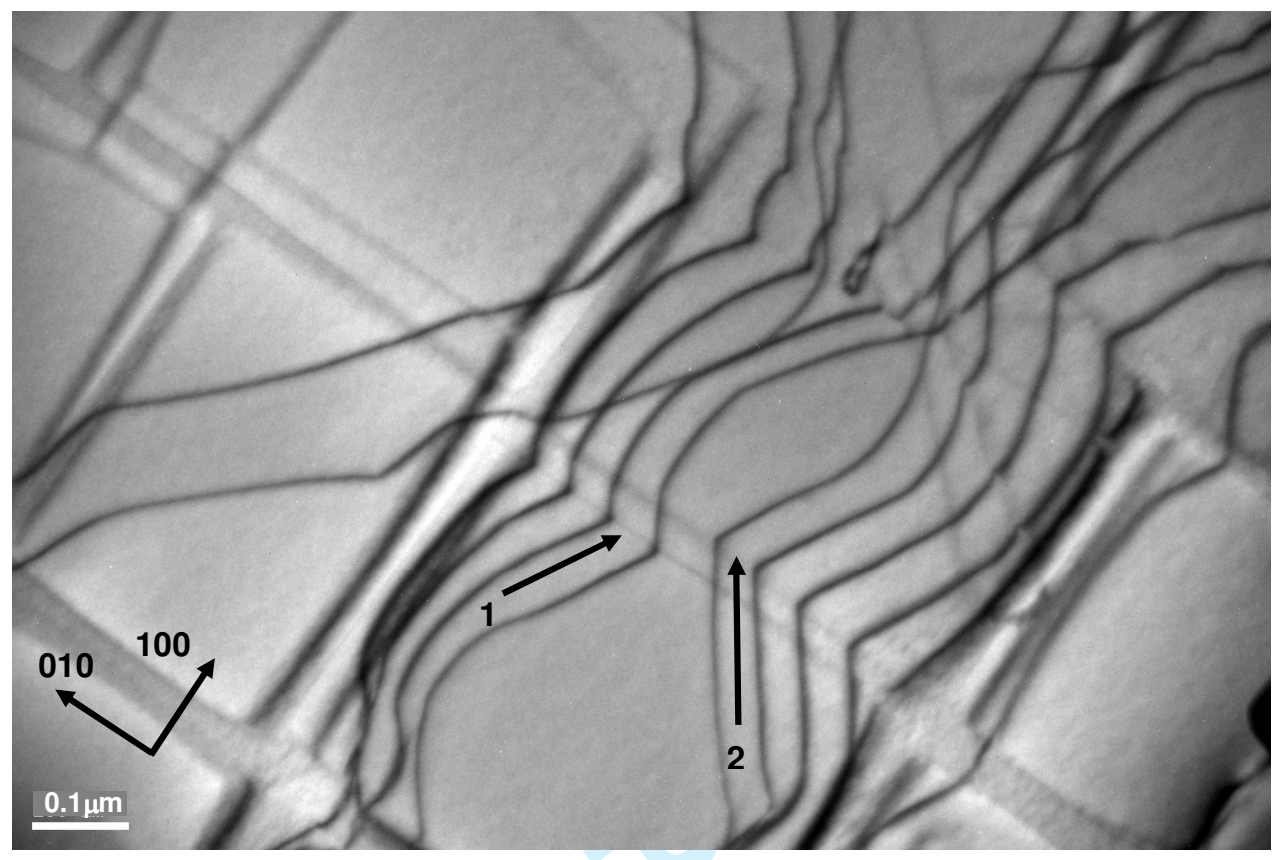

Figure 4. Interfacial dislocations with $\vec{b}=a / 2$ [101], propagating in [010] average direction. Cross slip takes place directly on the edge of C-channels. TMS $138,1100^{\circ} \mathrm{C}, 137 \mathrm{MPa}, 2 \mathrm{~h}, 0.04 \%$, cross section. $\mathrm{BF}, \vec{k}_{0}=[100], \vec{g}=020$. 

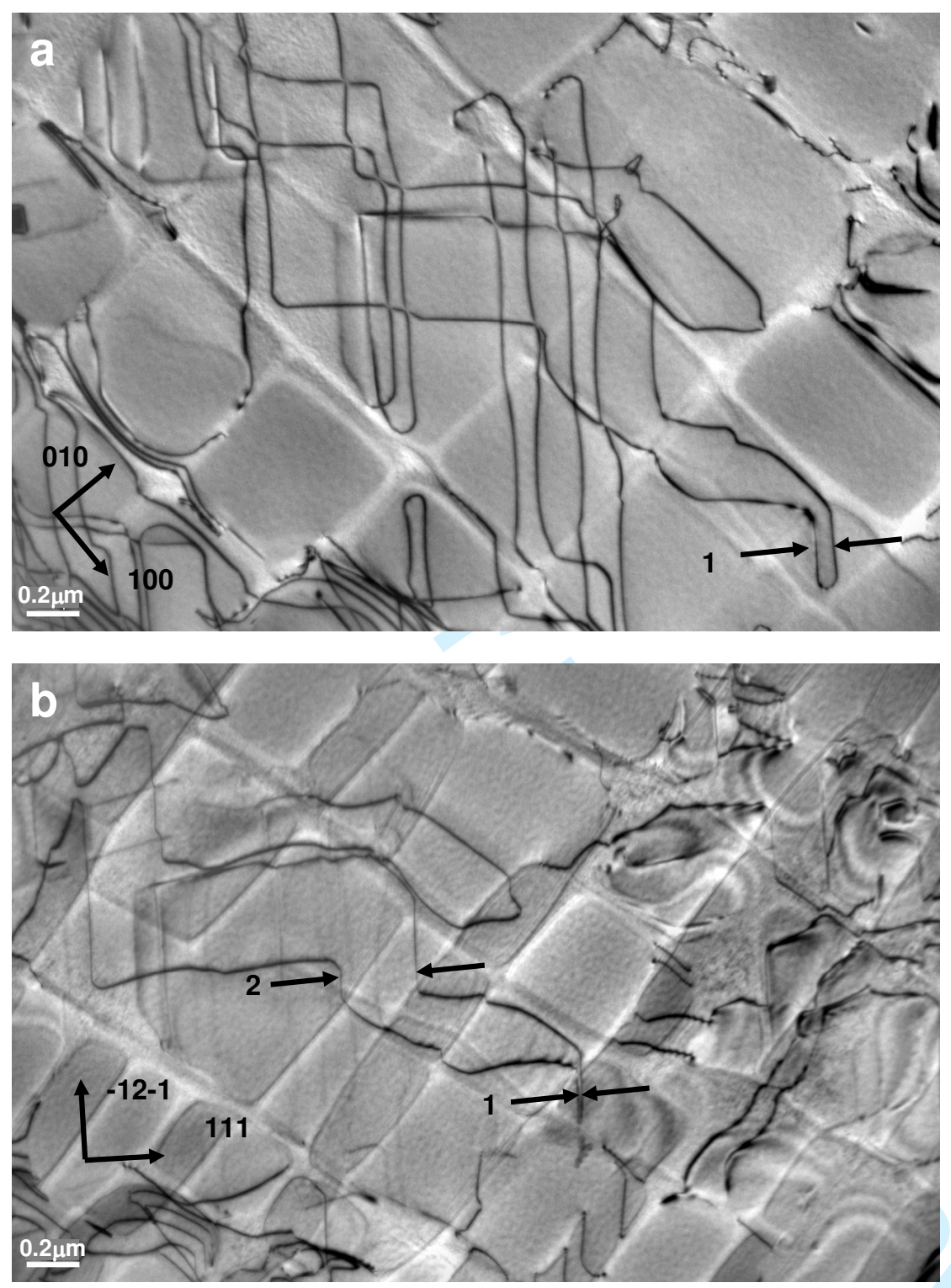

Figure 5. Dislocation loops in SRR 99 creep deformed at $980^{\circ} \mathrm{C}, 200 \mathrm{MPa}, 45.4 \mathrm{~h}, 0.3 \%$.

a) Viewing direction perpendicular onto the (001) interface. Cross section, BF, $\vec{k}_{0}=[001], \vec{g}=0 \overline{2} 0$.

b) Foil tilted with (111) glide plane edge on. BF, $\vec{k}_{0}=[\overline{1} 01], \vec{g}=1 \overline{1} 1$. 

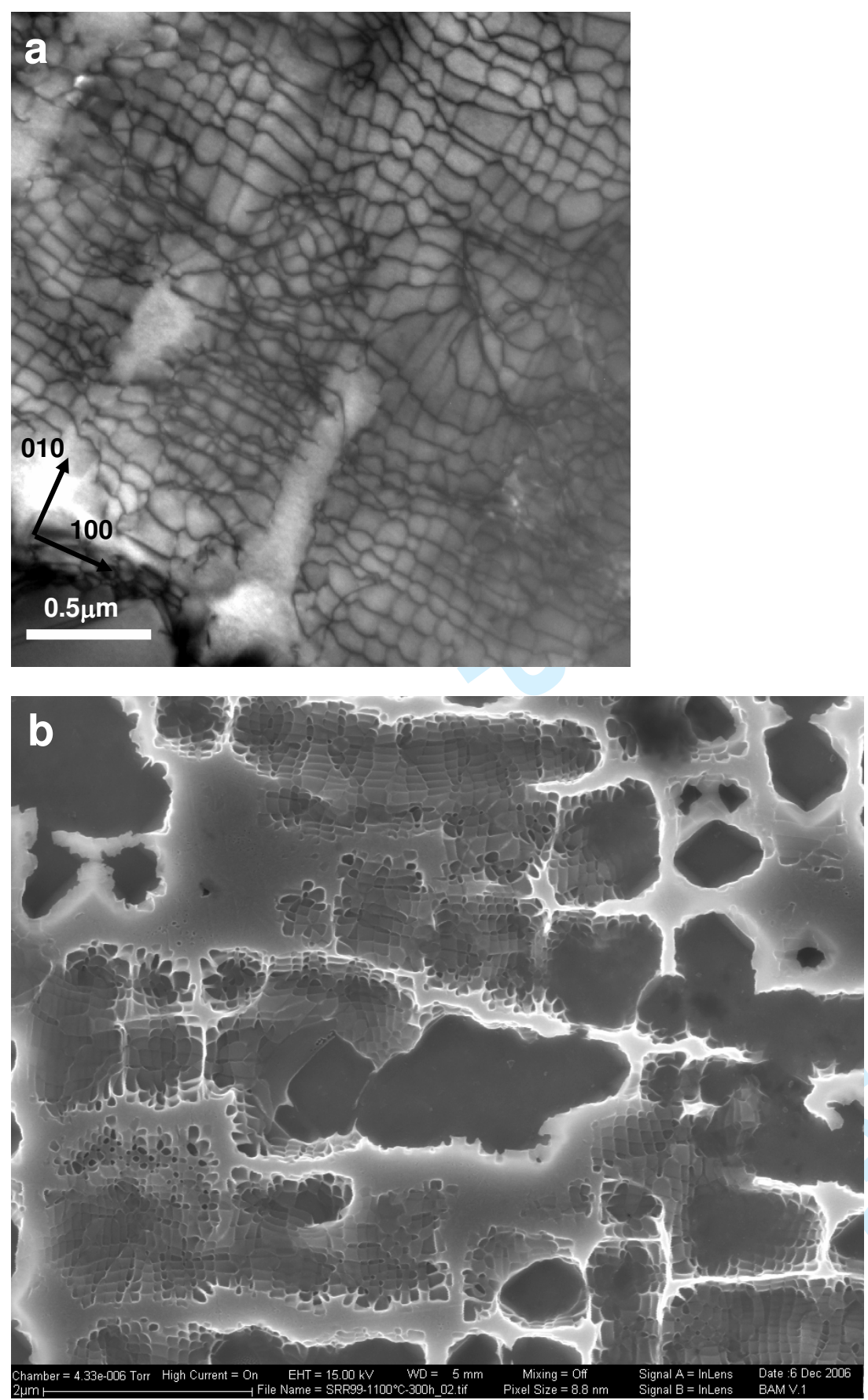

Figure 6. Square interfacial networks in SRR99, annealed at $1100^{\circ} \mathrm{C}$ for $300 \mathrm{~h}$. (001) cut, imaged either by TEM in BF, multibeam (a) or by SEM (b). 


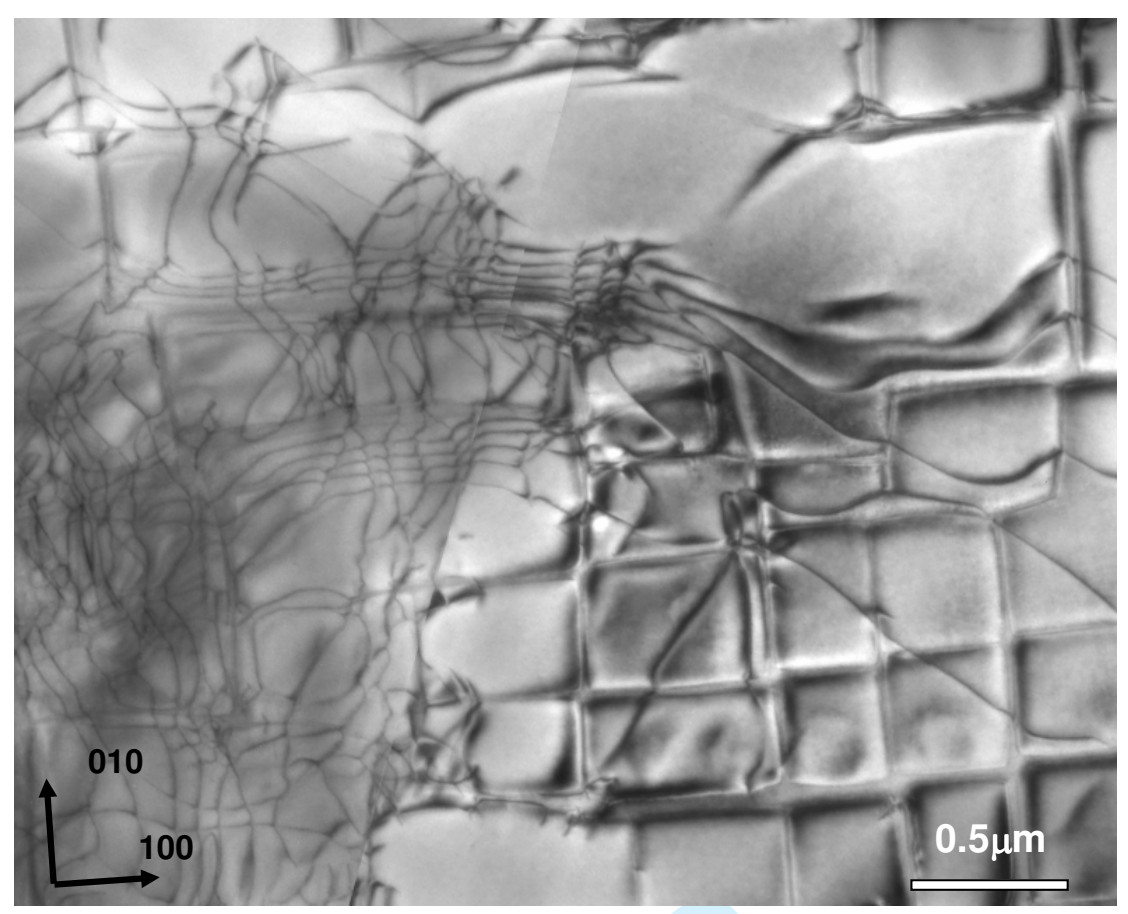

Figure 7. Dislocation loops align in $\langle 100\rangle$ directions and form square networks. TMS138, $1100^{\circ} \mathrm{C}, 137$ $\mathrm{MPa}, 2 \mathrm{~h}, 0.04 \%$. Cross section, BF, $\vec{k}_{0}=[001], \vec{g}=220$. Tilted line in the middle results from the montage of two images. 
1 3 4 5

Figure 8. Structural model for FEM calculations, given in a (100) projection. The analysed area is cubic and extends from the center of a $\gamma^{\prime}$ cube to the center of the crossing matrix channels.

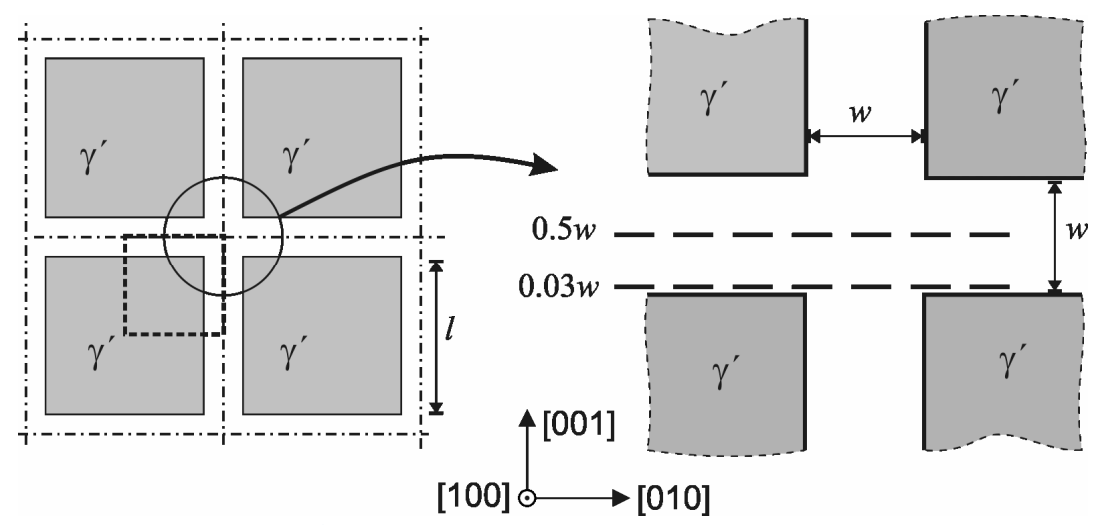


1

2

3

4

5

6

7

8

9

10

11

12

13

14

15

16

17

18

19

20

21

22

23

24

25

26

27

28

29

30

31

32

33

34

35

36

37

38

39

40

41

42

43

44

45

46

47

48

49

50

51

52

53

54

55

56

57

58

59

60
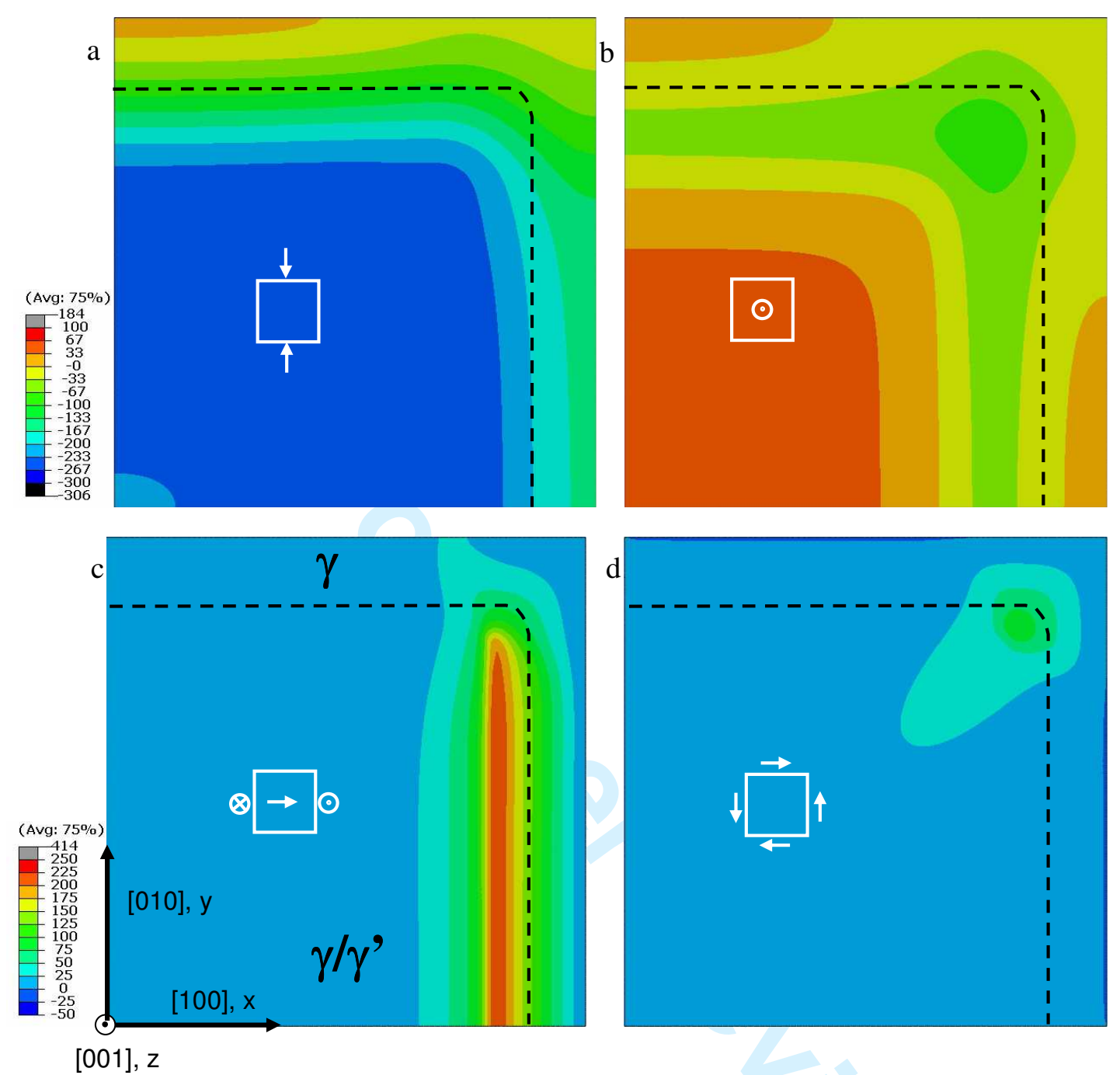

Figure 9. Distributions of misfit stresses in MPa in (001) sections of the P-channel at different distances from the interface: components $\sigma_{22}^{m}$ (a) and $\sigma_{33}^{m}$ (b) at the distance $0.5 \mathrm{w}$, components $\sigma_{13}^{m}$ (c) and $\sigma_{12}^{m}$ (d) at the distance $0.03 w$. The positions of the sections are shown in Fig. 8. 


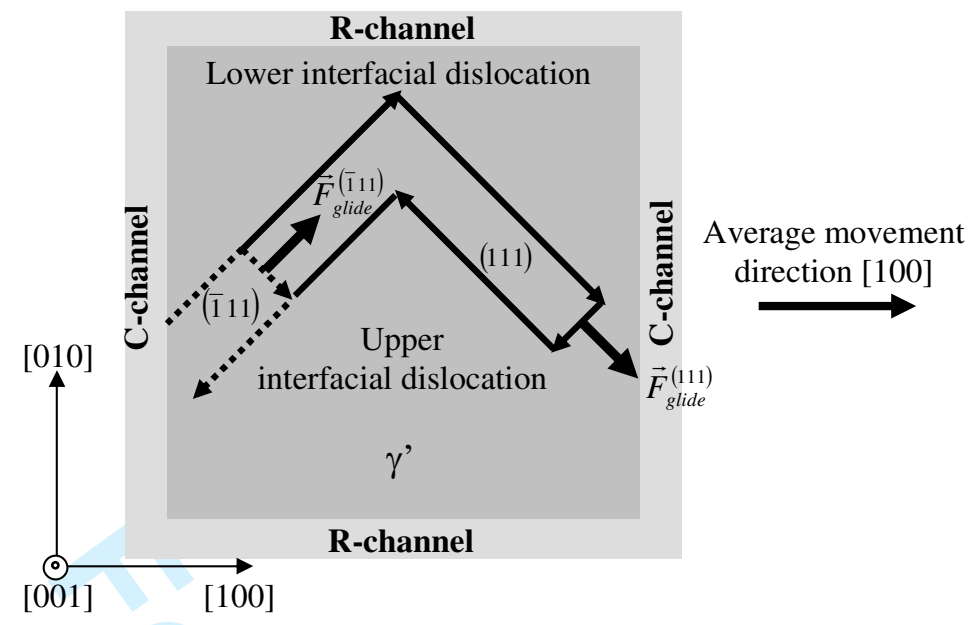

Figure 10. Kink in a dislocation loop. The loop moves in a P-channel lying between two $\gamma^{\prime}$ cubes. 
1

3 4 5 6 7

8

9

a

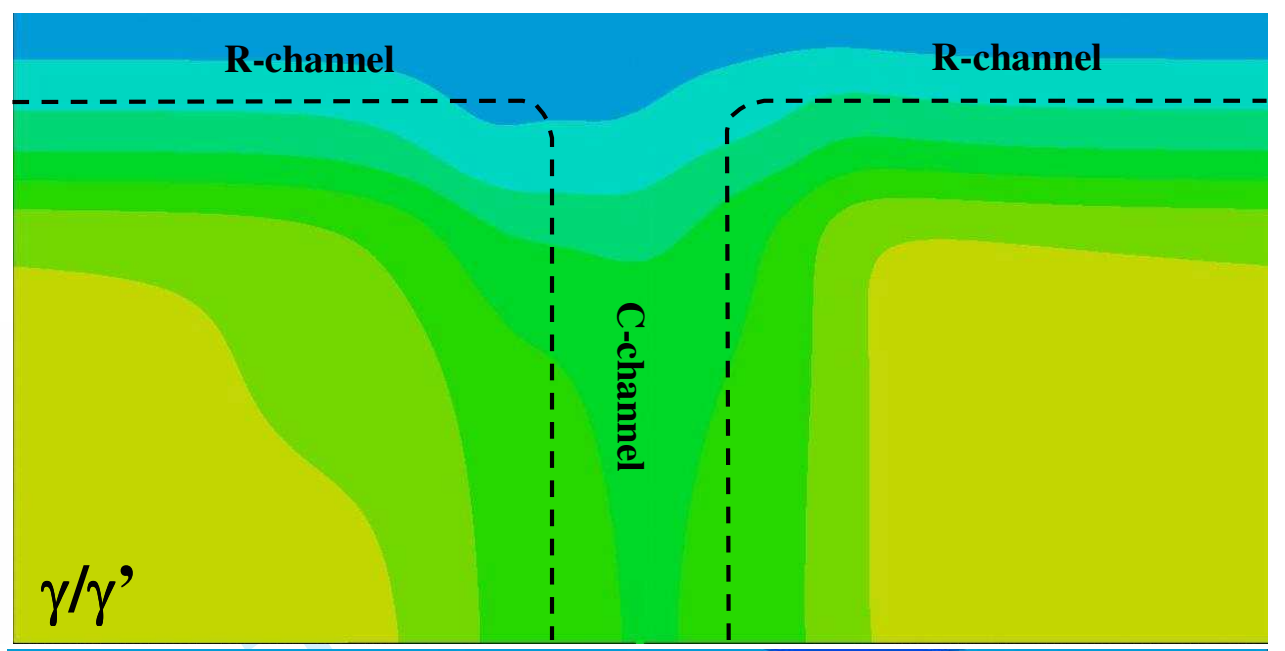

b

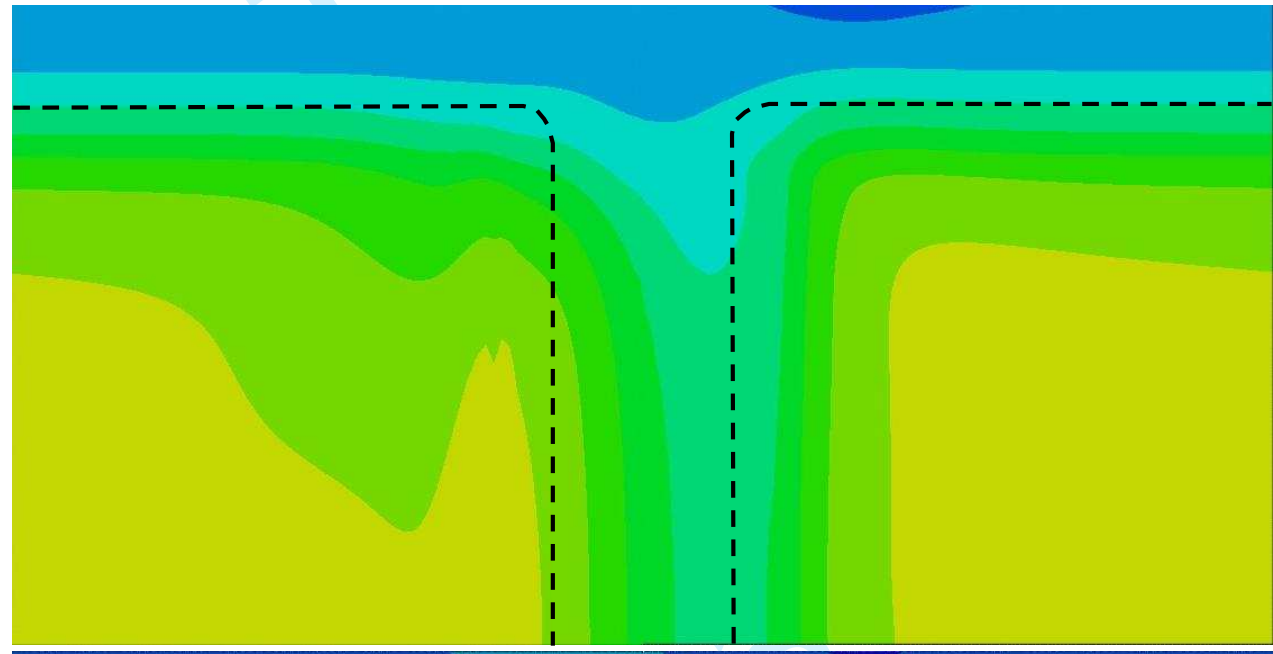

c

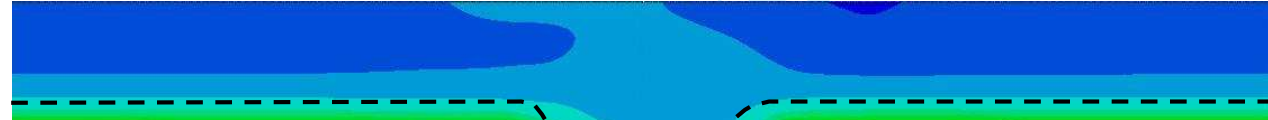

[001], z

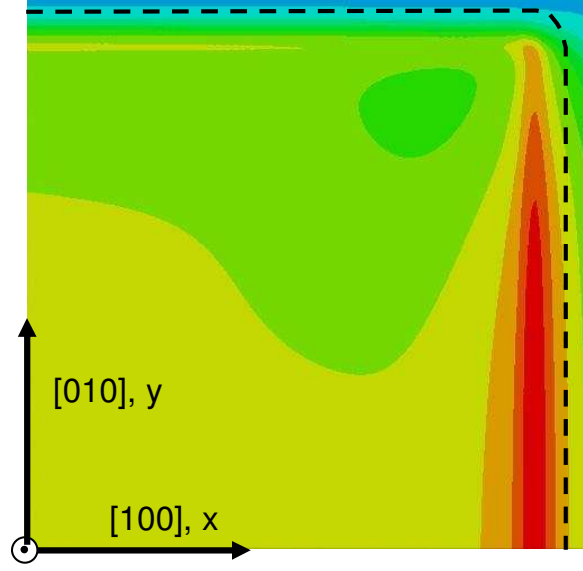

Figure 11. Distributions of RSS $\tau_{(111)}^{m}$ in MPa in 3 cross sections along the (001)-channel: in the channel middle $0.5 w$ (a), $0.25 w$ from the (001) interface (b) and very close to the interface $0.03 w$ (c). 

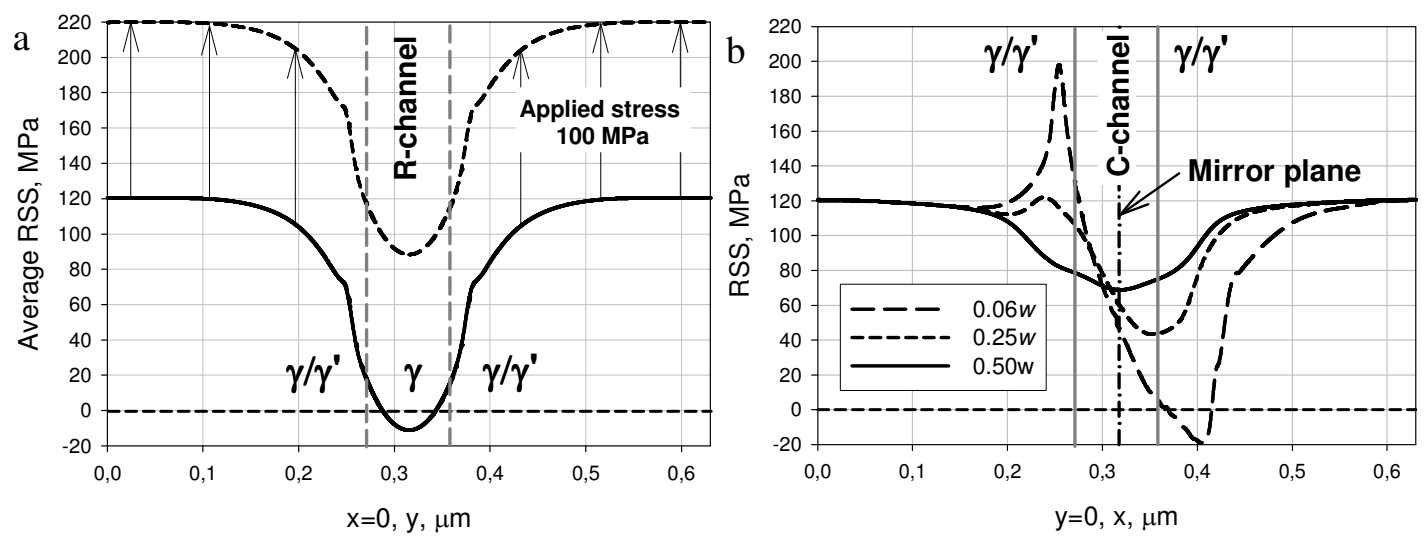

Figure 12. Resolved shear stresses $\operatorname{RSS}(x, y, z)$ acting on dislocations gliding in the P-channel (001). a) $\tau_{(111)}^{m}=\tau_{(\overline{1} 11)}^{m}$ for $x=0$ in $y$-direction across the R-channel (010).

b) $\tau_{(111)}^{m}$ for $y=0$ in $x$-direction across the C-channel (100). RSS is plotted for 3 distances from the $\gamma / \gamma^{\prime}$ surface.

The coordinates $x=0, y=0$ belong to the corner bottom-left in Fig. 11c. 


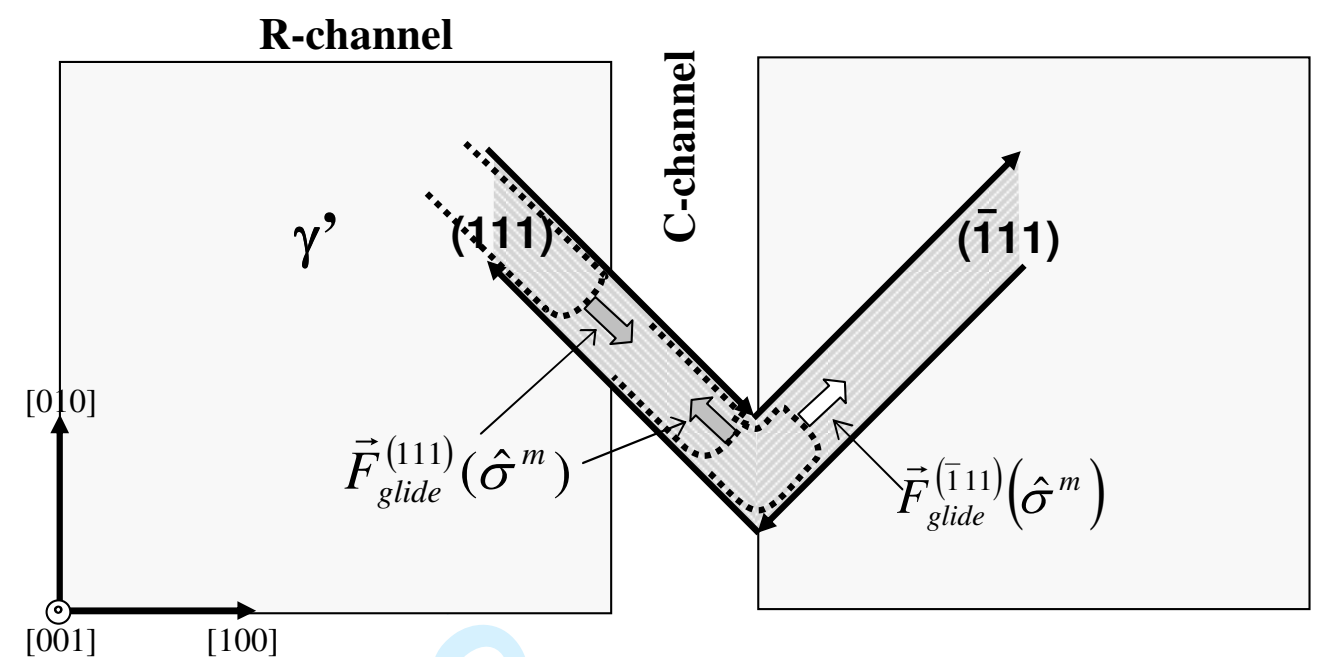

Figure 13. Cross glide when crossing the C-channel (100). 
Figure 14. Distribution of $\tau_{(111)}^{m}$ in MPa on a longitudinal (010) section with $\mathrm{y}=0$. (Middle of the cube edge in [010] direction). 
Figure 15. Distribution of $F_{[010]}\left(\hat{\sigma}^{m}\right)$ in MPa on a cross section for $\sigma_{33}^{a}=0 . F_{[010]}$ drives the dislocation segment with $\vec{b}=\frac{a}{2}[0 \overline{1} 1]$ and $\vec{\xi}=[100]$ towards the [100] edge. $(|\vec{b}|$ is taken to be equal 1$)$. 